Article

\title{
Improvement in Thermomechanical Reliability of Low Cost Sn-Based BGA Interconnects by Cr Addition
}

\author{
Junghwan Bang ${ }^{1,2, *}$, Dong-Yurl Yu ${ }^{1}$, Ming Yang ${ }^{1}$, Yong-Ho Ko ${ }^{1}$, Jeong-Won Yoon ${ }^{1}$, \\ Hiroshi Nishikawa ${ }^{3}$ and Chang-Woo Lee ${ }^{1}$ \\ 1 Micro-Joining Center, Korea Institute of Industrial Technology, 156 Gaetbeol-ro, Yeonsu-gu, \\ Incheon 22003, Korea; alpha0987@kitech.re.kr (D.-Y.Y.); yangming@kitech.re.kr (M.Y.); \\ yonghoko@kitech.re.kr (Y.-H.K.); jwyoon@kitech.re.kr (J.-W.Y.); cwlee@kitech.re.kr (C.-W.L.) \\ 2 Graduate School of Engineering, Osaka University, 2-1 Yamadaoka, Suita, Osaka 565-0871, Japan \\ 3 Joining and Welding Research Institute, Osaka University, 11-1 Mihogaoka, Ibaraki, Osaka 567-0047, Japan; \\ nisikawa@jwri.osaka-u.ac.jp \\ * Correspondence: nova75@kitech.re.kr; Tel.: +82-32-850-0217; Fax: +82-32-850-0210
}

Received: 11 July 2018; Accepted: 26 July 2018; Published: 27 July 2018

\begin{abstract}
The exemption of Pb-bearing automobile electronics in the End of Life Vehicle (ELV) directive has recently expired, bring an urgent need to find $\mathrm{Pb}$-free alloys that can maintain good performance under high-temperature and vibration conditions for automobile application. In this study, a new lead-free solder, $\mathrm{Sn}-0.7 \mathrm{Cu}-0.2 \mathrm{Cr}$ (wt.\%) alloy, was developed. To evaluate the thermomechanical reliability of the new solder alloy in automobile electronics, a thermal shock test was performed. The results show that the presence of $\mathrm{Cr}$ in solder inhibits the growth of interfacial $\mathrm{Cu}_{3} \mathrm{Sn}$ layer and the formation of Kirkendall voids, which effectively improves the joint reliability under intense thermal shock condition compared with the commercial SAC305 and SC07 solders. Specifically, the shear strength of the $\mathrm{Sn}-0.7 \mathrm{Cu}-0.2 \mathrm{Cr} / \mathrm{Cu}$ solder joints was higher by $23 \%$ and $44 \%$ than that of SAC305 and SC07 solder joints after 2000 cycles of thermal shock at $1 \mathrm{~m} / \mathrm{s}$ shear speed.
\end{abstract}

Keywords: lead-free solder; IMC (intermetallic compounds); thermal shock; shear strength

\section{Introduction}

Due to environmental concerns, legislation has come into effect, which was passed by the European Union in 2002, to ban the use of $\mathrm{Pb}$ and other toxic materials in electronic packaging [1,2]. Extensive searches for $\mathrm{Pb}$-free solder alloys have been conducted over the past two decades. Nowadays, a Pb-free process has been successfully achieved in consumer electronics production, whereas Pb-bearing solders are still used in the vehicles industry because of the reliability and safety concerns of $\mathrm{Pb}$-free solder alternatives [3,4]. However, this exemption ceases to exist with the release of the latest End of Life Vehicle (ELV) directive, in which some new restrictions explicitly demand that $\mathrm{Pb}$-bearing solder cannot be used in automotive electronics after 1 January 2016 [5]. In this context, how to improve the lead-free solder reliability in the automotive electronics application has become a research hotspot.

Recently, SnAgCu (SAC) solders have been most widely used in automobile electronics [5]. In terms of wettability and operation temperature, the SAC solders perform well. However, due to numerous brittle $\mathrm{Ag}_{3} \mathrm{Sn}$ intermetallic compounds (IMC) existing in the matrix, the SAC solder exhibits poor drop reliability, which is a significant threat, because the joints are always subject to vibrations of $3 \mathrm{Grms}$ to $20 \mathrm{Grms}$ in actual operation conditions [6]. Additionally, cost is another important factor that limits the SAC solder application. It should be noted that Ag is a noble metal, whose price is 
approximately 30 times higher than that of Sn. A 1\% reduction of Ag in a solder alloy results in at least a $15 \%$ reduction of the total solder cost. Currently, commercial imperatives to reduce costs have raised considerable interest in lowering the Ag content of SAC solder alloys to reduce the base alloy cost, especially in the context of decreasing profits in electronics manufacturing due to intense competition [7-9]. In this context, Ag-free solders, specifically the eutectic SC07 solder, has attracted much attention in automotive electronic applications because of the low cost and good drop reliability. Unfortunately, the drawback of $\mathrm{Sn}-\mathrm{Cu}$ solder is also obvious. The IMC growth at the $\mathrm{SnCu} / \mathrm{Cu}$ interface is much faster than that at the SAC/Cu interface. A too-thick IMC layer deteriorates the solder joint reliability because the IMC is brittle and possess lots of defects, such as Kirkendall voids inside $[1,10]$. Therefore, the prevention of excessive growth of IMC is of interest to materials researchers. Recently, several research groups have focused on developing composite electronic interconnect materials doped with metallic (e.g., $\mathrm{Ni}, \mathrm{Ag}, \mathrm{Al}, \mathrm{Co}, \mathrm{Cr}$, etc.) [11-17] and ceramic $\left(\mathrm{Al}_{2} \mathrm{O}_{3}, \mathrm{ZrO}_{2}, \mathrm{CeO}_{2}\right.$, etc.) [17-19] particles to control their interfacial microstructure and mechanical properties. For example, a trace amount of $\mathrm{Cr}$ in lead-free $\mathrm{SnZn}$ solder could repress the atomic diffusion and therefore reduce the interfacial IMC growth $[15,16]$. However, the effect of $\mathrm{Cr}$ addition in the $\mathrm{SnCu} / \mathrm{Cu}$ system has not been systemically evaluated in the literature.

A novel Sn-0.7Cu-0.2Cr solder has been developed for automobile electronics applications [20]. In this study, to be better consistent with the practical application environment, the $\mathrm{Sn}-0.7 \mathrm{Cu}-0.2 \mathrm{Cr}$ solder was fabricated as BGA (ball grid array) solder balls and soldered on the prototype modules. After cycles of thermal shock testing, the microstructure evolution of the BGA solders was observed and the shear strength of the solder balls was measured. In addition, to evaluate the reliability of the $\mathrm{Sn}-0.7 \mathrm{Cu}-0.2 \mathrm{Cr}$ solder in the automobile electronics application, the microstructure and shear strength variation of the commercial SAC305 and SC07 solders under thermal shock conditions were evaluated for comparison.

\section{Experimental Procedures}

\subsection{Preparation of Samples}

SAC305, SC07 and SC-Cr alloys were prepared from pure (>99.99 wt.\%) metals by using induction heating in a high-vacuum argon atmosphere at $1100{ }^{\circ} \mathrm{C}$ for $1 \mathrm{~h}$. Then, solder balls with diameters of $300 \mu \mathrm{m}$ were fabricated by using gas atomizing methods. Cu pads with an organic solderability preservative (OSP) surface finish on flame retardant (FR-4) boards was employed as solder wetting substrates. The OSP layer was $0.3 \mu \mathrm{m}$ in thickness and the bottom $\mathrm{Cu}$ layer was $230 \mu \mathrm{m}$ in diameter and $20 \mu \mathrm{m}$ in thickness. For sample preparation, the solder balls were coated with some flux, placed on the $\mathrm{Cu}$ pad and then reflowed by using an 9-zone reflow machine (1809-EXL; Heller, Florham Park, NJ, USA). After reflow, the test samples were cooled to room temperature in air. Figure 1 shows the setting temperatures and the real reflow profile for the SC-Cr, which is obtained by a reflow profile checker installed in the reflow machine. The peak temperatures of the SAC305, SC07 and SC-Cr solders were 250, 255 and $260.5{ }^{\circ} \mathrm{C}$, respectively. Table 1 listed the processing parameters. Some of the samples were tested in a VT 7006 chamber (Votsch, Berlin, Germany) for 500 to 2000 shocks at a cyclic temperature range of $-45-+125^{\circ} \mathrm{C}$, with each shock lasting $20 \mathrm{~min}$ (JESD22-104; JEDEC, Arlington, VA, USA).

After soldering and thermal shock testing, the samples were mounted in epoxy and polished to reveal the interfaces and internal microstructures. The samples were then etched with 3 vol. $\% \mathrm{HNO}_{3}$ and 2 vol. \% $\mathrm{HCl}$ (in ethanol) solution for a few seconds to reveal the cross-sectional microstructures. 


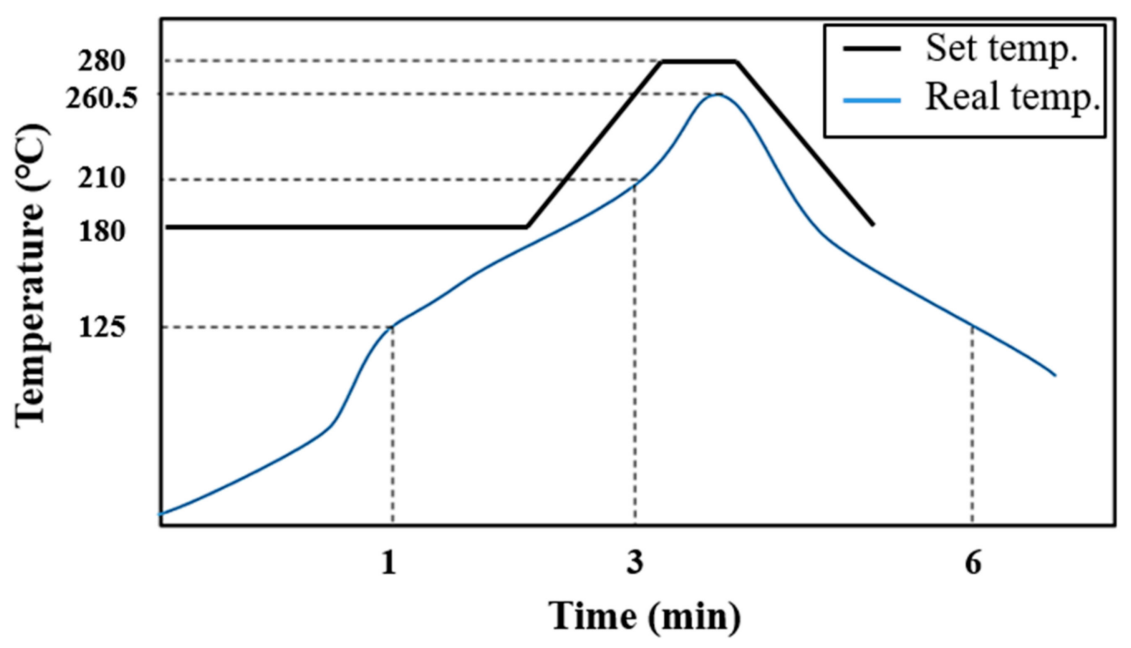

Figure 1. Reflow profile for SC-Cr/Cu solder joints.

Table 1. Reflow conditions.

\begin{tabular}{cccc}
\hline Solder & $\begin{array}{c}\text { Pre-Heating } \\
\text { Time (s) }\end{array}$ & $\begin{array}{c}\text { Duration Time above } \\
\text { Melting Temperature (s) }\end{array}$ & Peak Reflow Temperature $\left({ }^{\circ} \mathrm{C}\right.$ ) \\
\hline Sn-3.0Ag-0.5Cu & 107 & 53 & 250 \\
Sn-0.7Cu & 73 & 47 & 255 \\
Sn-0.7Cu-0.2Cr & 73 & 47 & 260.5 \\
\hline
\end{tabular}

\subsection{Characterization of the Solder/Cu Microstructure}

Scanning electron microscopy (SEM; S-4700, Hitachi, Tokyo, Japan), together with energy dispersive X-ray spectroscopy (EDX; EDAX Genesis XM2 60, AMETEK, Mahwah, NJ, USA), was employed to characterize the IMC microstructure. For kinetic studies, the IMC thicknesses were measured from the SEM images of the metallographic cross-sections using the following image analysis procedure [7,8]: (1) an SEM image of each sample was obtained at the appropriate magnification; (2) the grayscale SEM image was enhanced using Adobe Photoshop (CS6, Adobe systems, San Jose, CA, USA, 2017) to identify the interfaces between the different layers; and (3) the mean thickness $\left(H_{\mathrm{IMC}}\right)$ of individual layers was calculated using the following equation:

$$
H_{\text {IMC }}=H_{\text {SEM }} \times N_{\text {IMC }} / N_{\text {SEM }}
$$

where $H_{\text {SEM }}$ is the actual height of the SEM image, and $N_{\text {IMC }}$ and $N_{\text {SEM }}$ are the numbers of pixels in the IMC layers and the entire image, respectively.

\subsection{Mechanical Tests}

To evaluate the mechanical properties of solder joints after thermal shocks, ball shear tests were conducted at shear heights of $50 \mu \mathrm{m}$ with shear speed of $0.0002 \mathrm{~m} / \mathrm{s}, 0.01 \mathrm{~m} / \mathrm{s}, 0.1 \mathrm{~m} / \mathrm{s}$ and $1 \mathrm{~m} / \mathrm{s}$ using a bonding tester (PTR-1101, Rhesca Co., Tokyo, Japan), as shown in Figure 2. The shear force value was estimated by averaging 20 solder balls. After shear testing, all the fracture surfaces were observed in top and cross-section views using SEM. 


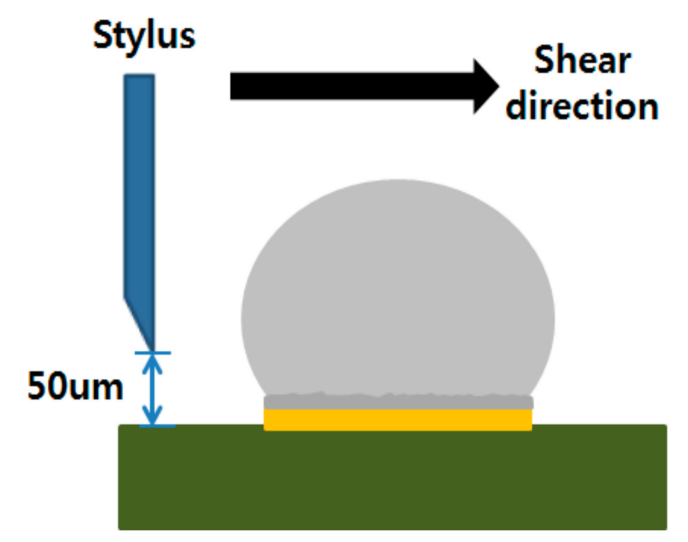

Figure 2. Schematic illustration of solder ball shear test.

\section{Results and Discussion}

\subsection{Interfacial Microstructure}

Figure 3 shows the cross-sectional microstructures of the IMC layers formed at SAC305/Cu, SC07/Cu and SC-Cr/Cu interfaces during thermal shock testing. Generally, the interfacial IMC became thicker and flatter with increasing thermal shocks. Compared with the interfacial IMC formed in the three reaction systems, the addition of $\mathrm{Cr}$ effectively inhibited interfacial IMC growth, especially the $\mathrm{Cu}_{3} \mathrm{Sn}$ IMC growth. Specifically, very few $\mathrm{Cu}_{3} \mathrm{Sn}$ IMC and Kirkendall voids were detected at the SC-Cr/Cu interface, even after 2000 cycles of thermal shock testing, whereas the $\mathrm{Cu}_{3} \mathrm{Sn}$ and Kirkendall voids were significant at the SAC305/Cu and SC07/Cu interfaces after 1000 cycles. To quantify the difference, the thicknesses of the IMC layers formed in the three reaction systems were measured using imaging analysis methods. Compared with the results plotted in Figure 4, Cr inhibited the interfacial IMC growth primarily by slowing down the $\mathrm{Cu}_{3} \mathrm{Sn}$ growth.

Fundamentally, the formation and growth of the interfacial IMC growth is caused by the $\mathrm{Cu}$ and Sn diffusion through the interface. To figure out how $\mathrm{Cr}$ inhibits the interfacial IMC growth, its effects on the $\mathrm{Cu}$ and $\mathrm{Sn}$ diffusion must be clarified. Next, the amounts of $\mathrm{Cu}$ and $\mathrm{Sn}$ atoms in the interfacial IMC layers were separately calculated for comparison as follows [21,22]:

$$
\begin{aligned}
& M_{\mathrm{Cu}}=T_{\mathrm{Cu}_{6} \mathrm{Sn}_{5}} \cdot \rho_{\mathrm{Cu}_{6} \mathrm{Sn}_{5}} \cdot v_{\mathrm{Cu} / \mathrm{Cu}_{6} \mathrm{Sn}_{5}}+T_{\mathrm{Cu}_{3} \mathrm{Sn}} \cdot \rho_{\mathrm{Cu}_{3} \mathrm{Sn}} \cdot v_{\mathrm{Cu}_{\mathrm{Cu}} \mathrm{Sn}} \\
& M_{\mathrm{Sn}}=T_{\mathrm{Cu}_{6} \mathrm{Sn}_{5}} \cdot \rho_{\mathrm{Cu}_{6} \mathrm{Sn}_{5}} \cdot v_{\mathrm{Sn} / \mathrm{Cu}_{6} \mathrm{Sn}_{5}}+T_{\mathrm{Cu}_{3} \mathrm{Sn}} \cdot \rho_{\mathrm{Cu}_{3} \mathrm{Sn}} \cdot v_{\mathrm{Sn} / \mathrm{Cu}_{3} \mathrm{Sn}}
\end{aligned}
$$

where $M$ is the total weight of the $\mathrm{Cu}$ or $\mathrm{Sn}$ element per unit area, $T$ is the thickness of the $\mathrm{Cu}_{6} \mathrm{Sn}_{5}$ or $\mathrm{Cu}_{3} \mathrm{Sn}$ layers, $v$ is the weight fraction of $\mathrm{Cu}$ or $\mathrm{Sn}$ in the $\mathrm{Cu}_{6} \mathrm{Sn}_{5}$ or $\mathrm{Cu}_{3} \mathrm{Sn}$ molecule and $\rho$ is the density of the $\mathrm{Cu}_{6} \mathrm{Sn}_{5}$ or $\mathrm{Cu}_{3} \mathrm{Sn} \mathrm{IMC}$, which is 8.45 or $8.97 \mathrm{~g} \cdot \mathrm{cm}^{3}$, respectively [23,24]. The diffusion rates of $\mathrm{Sn}$ and $\mathrm{Cu}$ were listed in Figure 5. The Sn diffusion rate are $0.38,0.14$ and $1.49 \mu \mathrm{g} \cdot \mathrm{mm}^{-2} / \mathrm{K} \cdot \mathrm{cycles}$ in SAC305/Cu, SC07/Cu and SC-Cr/Cu reactions, respectively. Correspondingly, the Cu diffusion rates are 3.13, 5.36 and $0.96 \mu \mathrm{g} \cdot \mathrm{mm}^{-2} / \mathrm{K} \cdot$ cycles in SAC305/Cu, SC $/ \mathrm{Cu}$ and SC-Cr/Cu reaction systems, respectively. The addition of $\mathrm{Cr}$ slightly increased $\mathrm{Sn}$ diffusion but significantly repressed the $\mathrm{Cu}$ diffusion under thermal shock test. From these results, we believe that $\mathrm{Cr}$ inhibited the solid-state interfacial IMC growth primarily through slowing down the $\mathrm{Cu}$ diffusion through the interface, although the root mechanism is still unclear. It is well known that only the $\mathrm{Cu}_{3} \mathrm{Sn}$ and $\mathrm{Cu}_{6} \mathrm{Sn}_{5}$ phases are formed at the SAC/Cu interface. Therefore, under similar Sn diffusion conditions, a lower $\mathrm{Cu}$ diffusion flux leads to repression of the $\mathrm{Cu}_{3} \mathrm{Sn}$ layer growth and the Kirkendall void formation at the interface in the SC-Cr/Cu reaction system, as shown in Figure 3. 


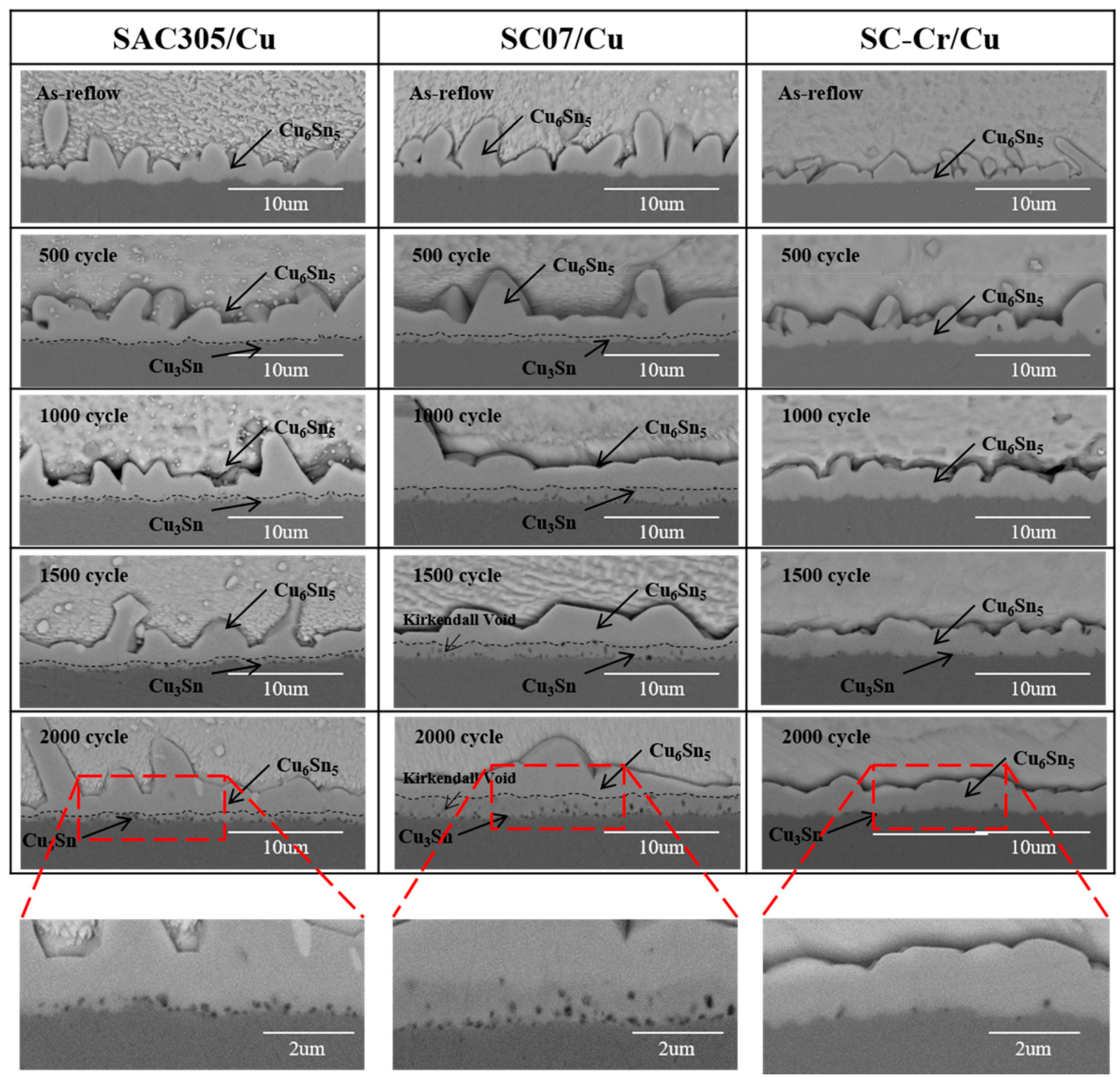

Figure 3. Representative SEM images showing the interfacial microstructures of the solder joints after various cycles of thermal shock.

Generally, many Kirkendall voids would be formed in the interfacial IMC layers, especially in the $\mathrm{Cu}_{3} \mathrm{Sn}$ layer, with prolonged thermal treatment, as shown in Figure 3. This is because $\mathrm{Cu}$ is the dominant diffusing species in the reaction and the competition in growth between $\mathrm{Cu}_{6} \mathrm{Sn}_{5}$ and $\mathrm{Cu}_{3} \mathrm{Sn}$ tends to favor the latter when the ratio of $\mathrm{Cu}$ to $\mathrm{Sn}$ is large in the sample [1]. The transformation of 1 molecule of $\mathrm{Cu}_{6} \mathrm{Sn}_{5}$ into 2 molecules of $\mathrm{Cu}_{3} \mathrm{Sn}$ will leave behind $3 \mathrm{Sn}$ atoms, which will attract 9 atoms of $\mathrm{Cu}$ to form 3 more molecules of $\mathrm{Cu}_{3} \mathrm{Sn}$. The vacancy flux needed to transport the $\mathrm{Cu}$ atoms will accumulate at the $\mathrm{Cu} / \mathrm{Cu}_{3} \mathrm{Sn}$ interface to form Kirkendall voids, which are undesirable in device applications [1]. Combined with the brittle nature of the IMC, such void defects could further deteriorate the interfacial connection of the solder joint under mechanical stress. Therefore, the inhibition of interfacial IMC growth and the Kirkendall formation in the $\mathrm{SC}-\mathrm{Cr} / \mathrm{Cu}$ reaction system is expected to improve the joint reliability, which will be discussed in the following section. 


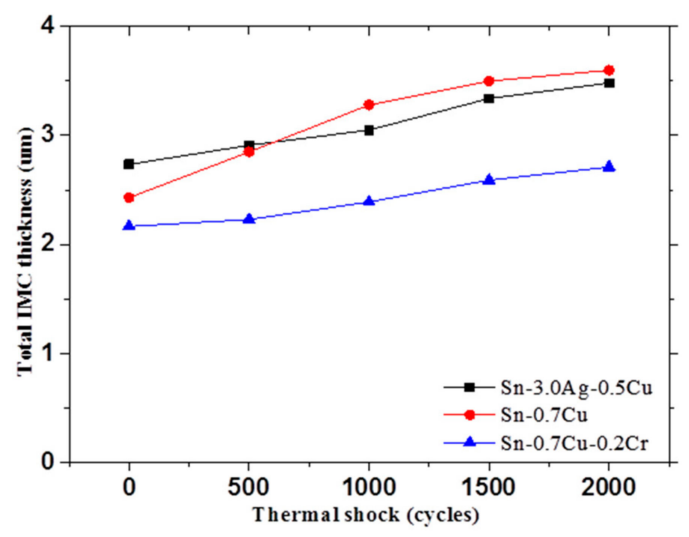

(a)

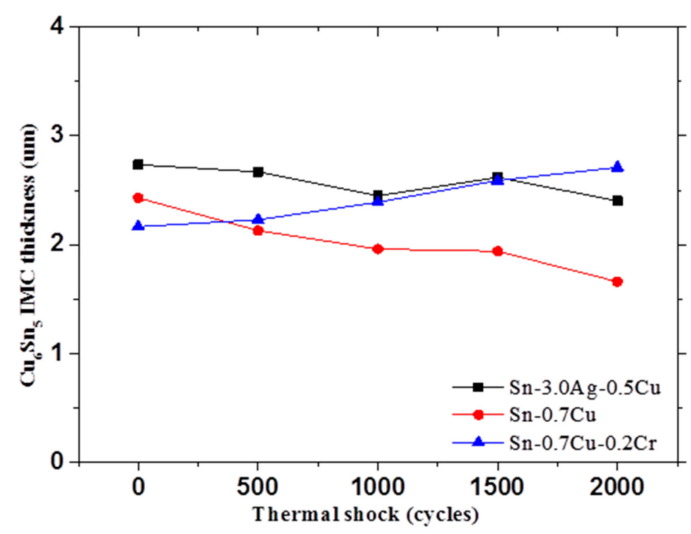

(b)

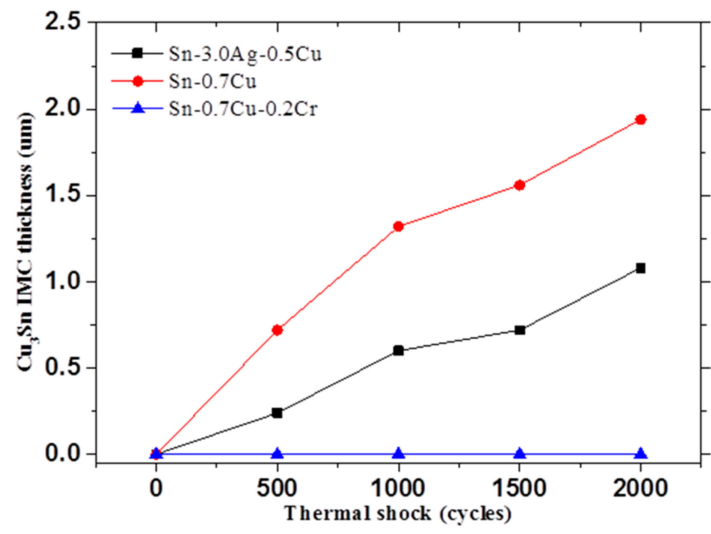

(c)

Figure 4. Plot of the thickness of IMC versus thermal shock cycles: (a) Total IMC thickness, (b) $\mathrm{Cu}_{6} \mathrm{Sn}_{5}$ IMC thickness, (c) $\mathrm{Cu}_{3} \mathrm{Sn}$ IMC thickness.

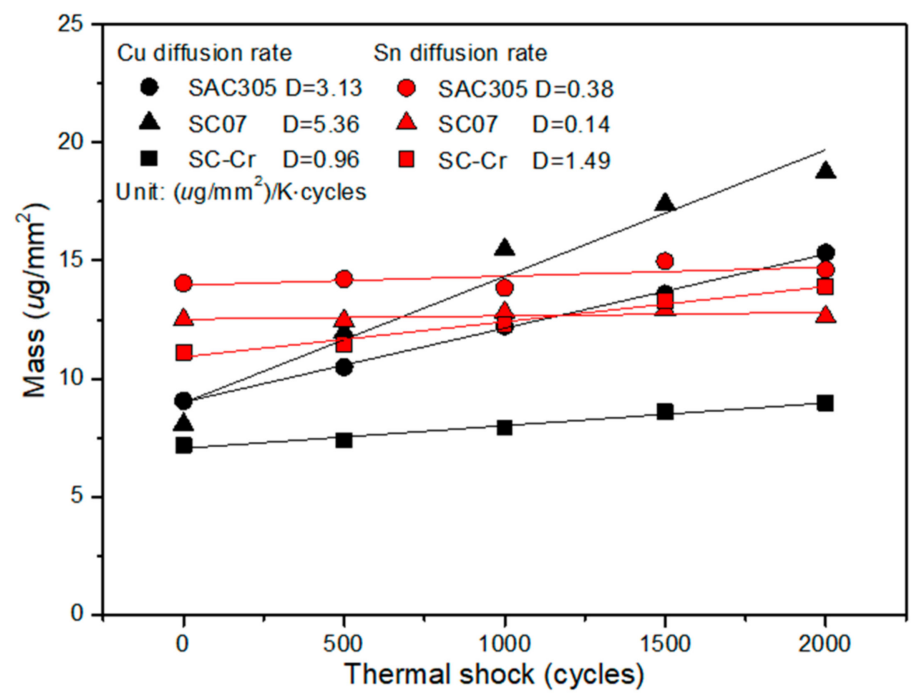

Figure 5. Plot of diffusivities of $\mathrm{Cu}$ and $\mathrm{Sn}$ versus thermal shock cycles.

\subsection{Mechanical Reliability}

The shear strength of the solder joints depends on the microstructure of the solder matrix and the interfacial connection. According to Kim's simulation results of shear tests at different shear speeds $[25,26]$, the shear force increased with increasing shear speed. At a low shear speed, the stress 
could be released though the deformation of the soft solder matrix, indicating that the joint strength should be more closely related to the strength of solder matrix; whereas at a high shear speed, due to the rapid deformation in solder matrix, a great stress would accumulate at the interface, indicating that the shear strength should be more related to the interfacial connection. Therefore, shear testing at shear speeds from $0.01 \mathrm{~m} / \mathrm{s}$ to $1 \mathrm{~m} / \mathrm{s}$ was conducted to examine the effects of solder microstructure and the interfacial IMC on the joint reliability.

Figure 6 shows the variation of the solder joint strength with prolonged thermal shock test at various shear speeds. Generally, the shear strength of the solder joints decreased with thermal shock test. These results are consistent with Kim's simulation [25,26] and Gain's experiments [27,28]. Although the trends in shear strength with thermal shock testing were similar, significant differences were observed in terms of shear speeds: at a low shear speed $(0.01 \mathrm{~m} / \mathrm{s})$, the SAC305/Cu solder joints exhibited highest strength, whereas SC-Cr/Cu solder joints show highest strength when the shear speed exceeds $0.1 \mathrm{~m} / \mathrm{s}$. As mentioned above, the difference should derive from the different fracture mechanisms under various shear speeds. To confirm this assumption, the fracture morphology of these solder joints was observed and classified, as shown in Figures 7 and 8. All the fractures exhibited ductile fracture morphology at a low shear speed, whereas the brittle fracture becomes dominant when the shear speed exceeds $0.1 \mathrm{~m} / \mathrm{s}$. The results indicate that the joint strength is determined by the solder matrix strength in the case of a low shear speed and more relies on the interfacial connection in the case of a high shear speed.
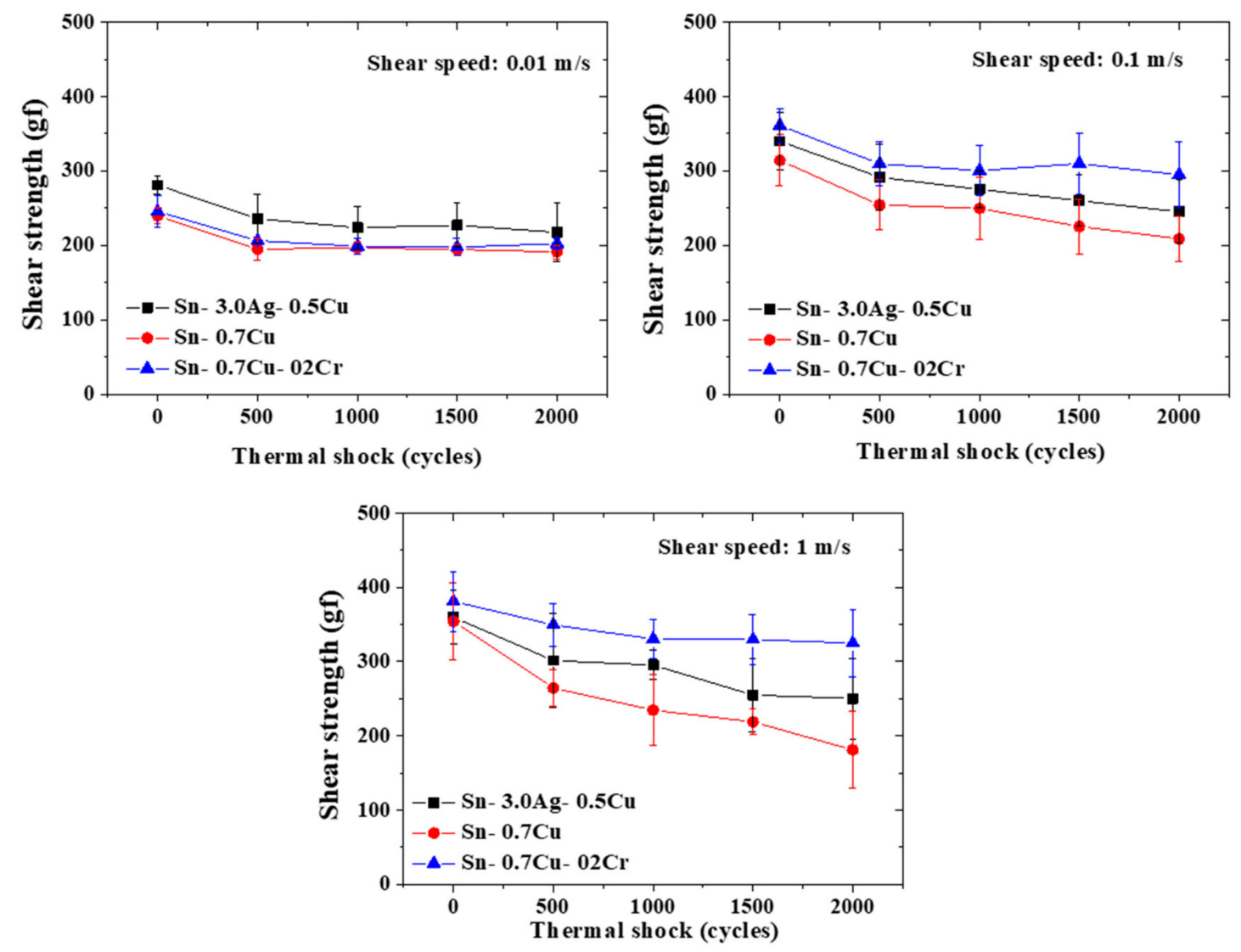

Figure 6. Shear strength of solder joints under various shear speeds. 


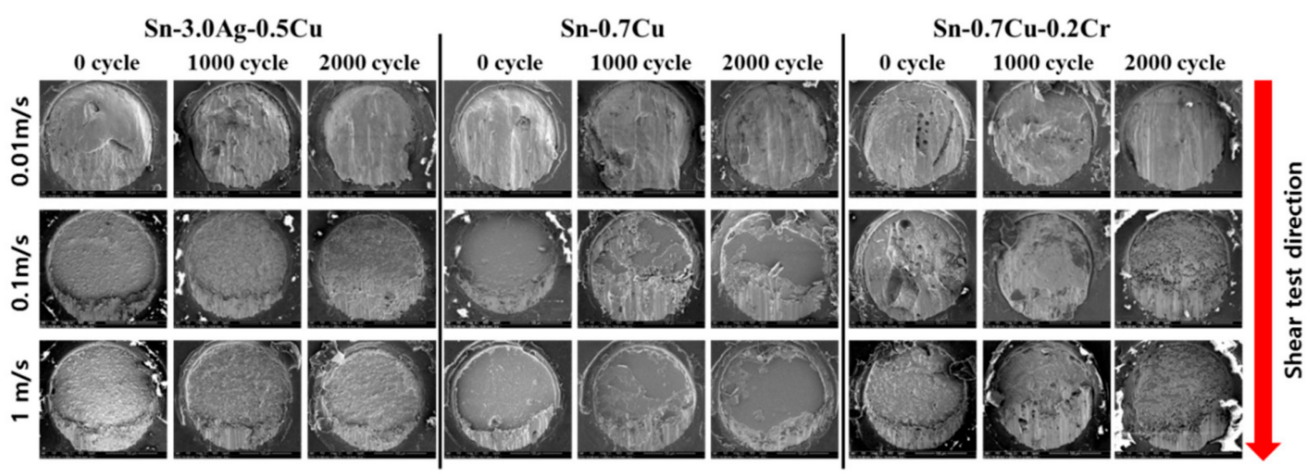

Figure 7. Fracture surfaces of the solder joints under various shear speeds.
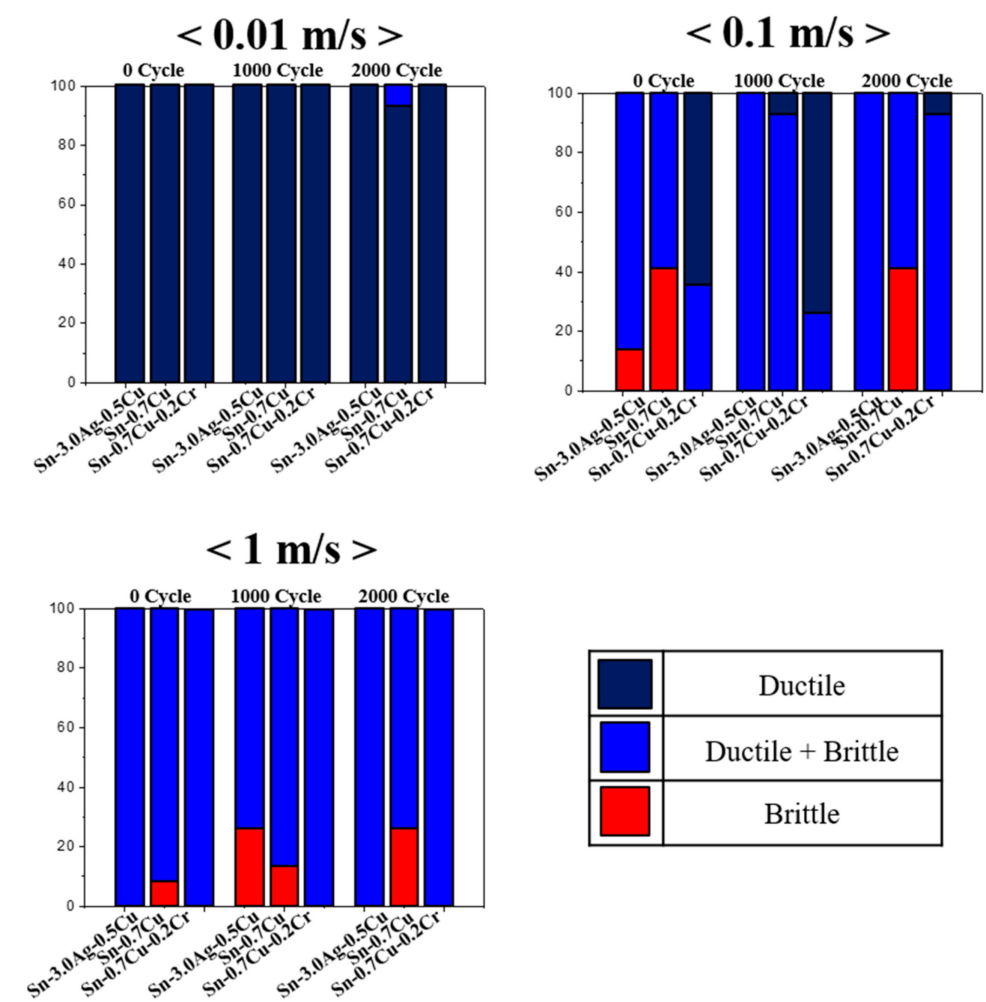

Figure 8. Statistics of fracture mode of solder joins under various shear speeds.

After solidification, the solder matrix is composed of $\beta$-Sn dendrites, eutectic areas, and some large precipitated IMC [21,22]. During soldering, $\mathrm{Cu}$ and $\mathrm{Ag}$ are dissolved in solder matrix, and due to the great difference in solubility, they precipitate during cooling in the form of $\mathrm{Ag}_{3} \mathrm{Sn}$ and $\mathrm{Cu}_{6} \mathrm{Sn}_{5}$ IMC, dispersing in solder matrix to form eutectic areas, as shown in Figure 9. Because these IMC is much harder than the solder matrix, these dispersed IMC could act as second-phase particles to pin the dislocation and block the crack propagation generated in shear test process, therefore enhancing the joint strength. It is known that more IMC exist in SAC305 solder than that in SC07 and SC-Cr solders. Correspondingly, the SAC305 solder exhibited higher hardness and strength than the other two solders (Figures 6 and 10) in the case of a low shear speed. With prolonged thermal shock, the solder microstructure coarsened, meaning that the strengthening effect caused by second-phase particles and grain boundaries gradually weakened. Therefore, the joint strength decreased with prolong thermal shock test. 
In the case of a high shear speed, a great stress generated in the solder matrix due to the rapid and great deformation and spread to the interfacial area during shear test. Because of the brittle property, the interfacial IMC is prone to crack under such intense stress. Generally, thicker interfacial IMC layers with more defects inside are more likely to crack. As shown in Figures 3 and 4 , the interfacial IMC became thicker with prolonged thermal shock times, causing a decrease in shear strength. Compared with the SAC305/Cu and SC07/Cu solder joints, the addition of Cr effectively inhibit interfacial IMC growth and Kirkendall void formation. Therefore, the strength of SC-Cr/Cu solder joints is much higher than the other two solder joints at a high-speed shear test. Specifically, the shear strength of the SC-Cr/Cu solder joints increased by $23 \%$ and $44 \%$ compared to that of SAC305 and SC07 solder joints after 2000 cycles of thermal shock at a shear speed of $1 \mathrm{~m} / \mathrm{s}$. Since the high-speed shear test could well reflect the mechanical reliability of BGA solder joints under dynamic loading [26], it is reasonable to expect that the SC-Cr solder joints could well perform under vibration condition in automotive applications.

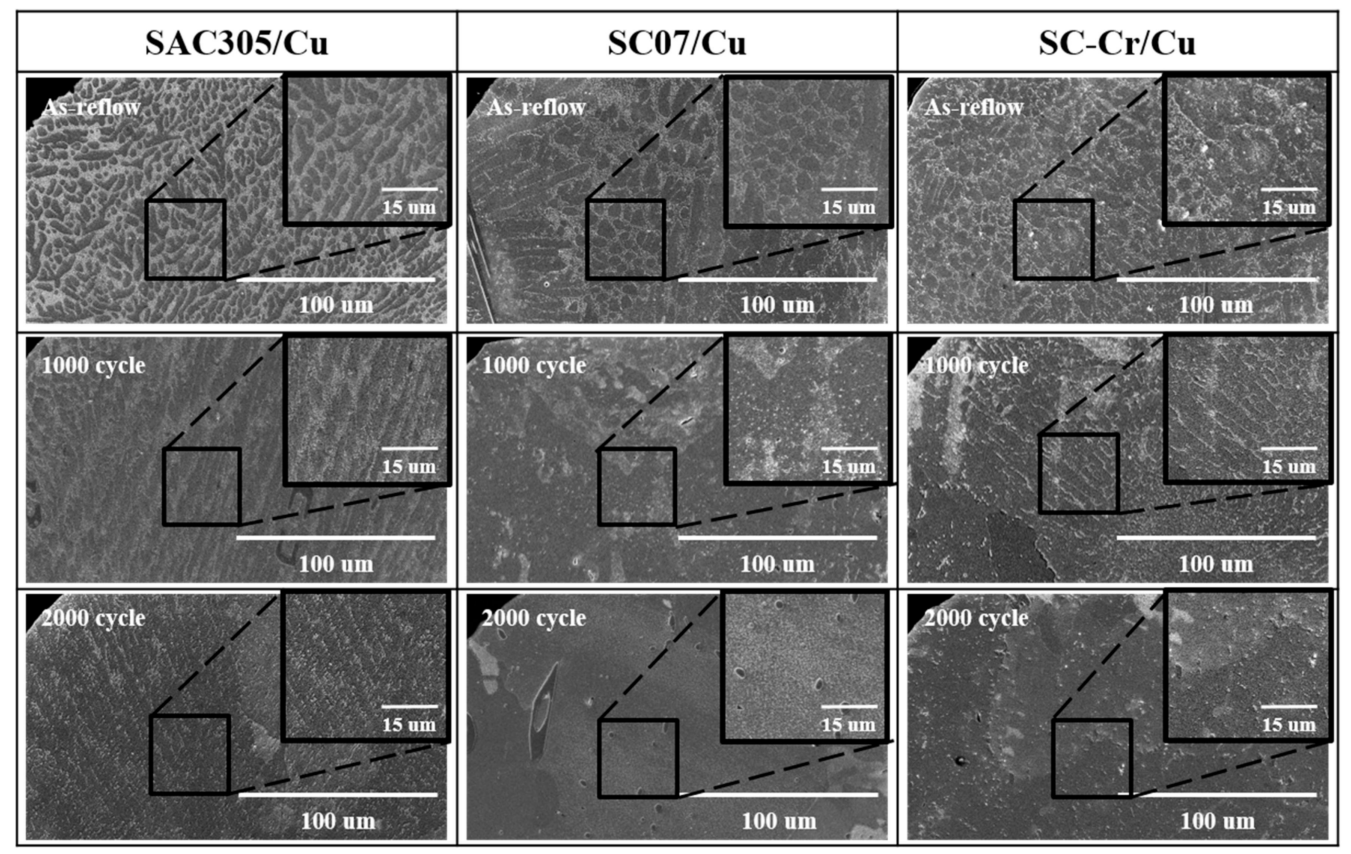

Figure 9. Microstructures of solder ball under various thermal shock cycles.

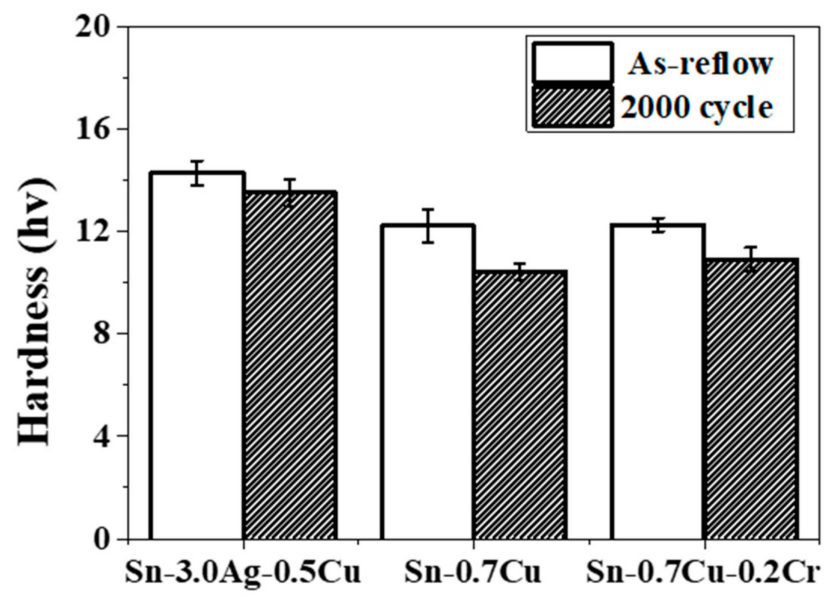

Figure 10. Hardness of different solders. 


\section{Conclusions}

In this study, the interfacial microstructure evolution and shear strength of $\mathrm{Sn}-0.7 \mathrm{Cu}-0.2 \mathrm{Cr}$ solder joints under intense thermal shock condition were investigated. The results are summarized as follows:

(1) The addition of $\mathrm{Cr}$ effectively slowed down the growth rate of the interfacial IMC layer during thermal shock compared with the Sn-0.7Cu solder.

(2) During thermal shock, the $\mathrm{Cr}$ in solder inhibits the growth of interfacial IMC layer and the formation of Kirkendall voids by slowing down the $\mathrm{Cu}$ diffusion at the interface.

(3) The shear strength of the solder joints decreased with thermal shock testing. The solder fracture is dominated by ductile fracture at a low shear speed, whereas it exhibited a more brittle type at a high shear speed.

(4) The reduced interfacial IMC thickness and Kirkendall voids in SC-Cr/Cu solder joints effectively improves the joint reliability under intense thermal shock conditions compared with the commercial SAC305/Cu and SC07/Cu solders. Specifically, the shear strength of the SC-Cr/Cu solder joints were much higher than that of SAC305 and SC07 solder joints after 2000 cycles of thermal shock at shear speed of $1 \mathrm{~m} / \mathrm{s}$.

Author Contributions: J.B., C.-W.L. conceived and designed the experiments; D.-Y.Y. performed the experiments; Y.-H.K., J.-W.Y. and M.Y. analyzed the data; J.B. and H.N. wrote the paper and edited.

Funding: This research was funded by Ministry of Commerce Industry and Energy in Korea government (Grant No. 10077336).

Conflicts of Interest: The authors declare no conflict of interest.

\section{References}

1. Tu, K.N. (Ed.) Solder Joint Technology: Materials, Properties, and Reliability; Springer: New York, NY, USA, 2007.

2. Zeng, K.; Tu, K.N. Six cases of reliability study of Pb-free solder joints in electronic packaging technology. Mater. Sci. Eng. R Rep. 2005, 38, 55-105. [CrossRef]

3. Zhang, Q.K.; Long, W.M.; Zhang, Z.F. Growth behavior of intermetallic compounds at $\mathrm{Sn}-\mathrm{Ag} / \mathrm{Cu}$ joint interfaces revealed by 3D imaging. J. Alloys Compd. 2015, 646, 405-411. [CrossRef]

4. Hurtony, T.; Almasy, A.S.L.; Len, A.; Kugler, S.; Bonyar, A.; Gordon, P. Characterization of the microstructure of tin-silver lead free solder. J. Alloys Compd. 2016, 672, 13-19. [CrossRef]

5. Hong, W.S.; Oh, C.; Kim, M.S.; Lee, Y.W.; Kim, H.J.; Hong, S.J.; Moon, J.T. Al and Si alloying effect on solder joint reliability in Sn-0.5Cu for automotive electronics. J. Electron. Mater. 2016, 45, 6150-6162.

6. Johnson, R.W.; Evans, J.L.; Jacobsen, P.; Thompson, J.R.; Christopher, M. The changing automotive environment: high-temperature electronics. IEEE Trans. Electron. Pack. Manuf. 2004, 27, 164-176. [CrossRef]

7. Yang, M.; Ji, H.; Wang, S.; Ko, Y.-H.; Lee, C.-W.; Wu, J.; Li, M. Effects of Ag content on the interfacial reactions between liquid $\mathrm{Sn}-\mathrm{Ag}-\mathrm{Cu}$ solders and $\mathrm{Cu}$ substrates during soldering. J. Alloys Compd. 2016, 679, 18-25. [CrossRef]

8. Ko, H.; Lee, J.D.; Yoon, T.; Lee, C.W.; Kim, T.S. Controlling interfacial reactions and intermetallic compound growth at the interface of a lead-free solder joint with layer-by-layer transferred grapheme. ACS Appl. Mater. Interfaces 2016, 8, 5679-5686. [CrossRef] [PubMed]

9. Zhang, S.; Yang, M.; Jin, M.; Huang, W.; Lin, T.; Peng, H.; Lin, P.; Paik, K.W. Mechanism of solder joint cracks in anisotropic conductive films bonding and solutions: Delaying hot-bar lift-up time and adding silica fillers. Metals 2018, 8, 42. [CrossRef]

10. Kim, J.Y.; Yu, J.; Kim, S.H. Effects of sulfide-forming element additions on the Kirkendall void formation and drop impact reliability of Cu/Sn-3.5Ag solder joints. Acta Mater. 2009, 57, 5001-5012. [CrossRef]

11. Gain, A.K.; Zhang, L. Microstructure, thermal analysis and damping properties of Ag and Ni nano-particles doped Sn-8Zn-3Bi solder on OSP-Cu substrate. J. Alloys Compd. 2014, 617, 779-786. [CrossRef]

12. Zhang, S.; Yang, M.; Wu, Y.; Du, J.; Lin, T.; Peng, H.; Huang, M.; Paik, K.W. A study on the optimization of anisotropic conductive films for Sn-3Ag-0.5Cu-Based flex-on-board application at a $250{ }^{\circ} \mathrm{C}$ bonding temperature. IEEE Trans. Comp. Pack. Manuf. 2018, 8, 1-9. [CrossRef] 
13. Fouzder, T.; Li, Q.; Chan, Y.; Chan, D. Interfacial microstructure and hardness of nickel (Ni) nanoparticle-doped tin-silver-copper ( $\mathrm{Sn}-\mathrm{Ag}-\mathrm{Cu})$ solders on immersion silver (Ag)-plated copper $(\mathrm{Cu})$ substrates. J. Mater. Sci. Mater. Electron. 2014, 25, 4012-4023. [CrossRef]

14. Chen, X.; Zhou, J.; Xue, F.; Bai, J.; Yao, Y. Microstructures and mechanical properties of Sn-0.1Ag-0.7Cu-(Co, $\mathrm{Ni}$, and $\mathrm{Nd}$ ) lead-free solders. J. Electron. Mater. 2015, 44, 725-732. [CrossRef]

15. Chen, X.; Hu, A.; Li, M.; Mao, D. Effect of a trace of $\mathrm{Cr}$ on intermetallic compound layer for tin-zinc lead-free solder joint during aging. J. Alloys Compd. 2009, 470, 429-433. [CrossRef]

16. Bi, J.; Hu, A.; Hu, J.; Luo, T.; Li, M.; Mao, D. Effect of $\mathrm{Cr}$ additions on interfacial reaction between the $\mathrm{Sn}-\mathrm{Zn}-\mathrm{Bi}$ solder and $\mathrm{Cu}$ /electroplated Ni substrates. Microelectron. Reliab. 2011, 51, 636-641. [CrossRef]

17. Zhang, L.; Tu, K.N. Structure and properties of lead-free solders bearing micro and nano particles. Mater. Sci. Eng. R Rep. 2014, 82, 1-32. [CrossRef]

18. Yakymovych, A.; Plevachuk, Y.; Švec, P., Sr.; Švec, P.; Janičkovič, D.; Šebo, P.; Janičkovič, D.; Šebo, P.; Beronská, N.; Roshanghias, A.; et al. Morphology and shear strength of lead-free solder joints with $\mathrm{Sn}_{3.0} \mathrm{Ag}_{0.5} \mathrm{Cu}$ solder paste reinforced with ceramic nanoparticles. J. Electron. Mater. 2016, 45, 6143-6149. [CrossRef]

19. Xing, W.Q.; Yu, X.Y.; Li, H.; Ma, L.; Zuo, W.; Dong, P.; Wang, W.X.; Ding, M. Effect of nano $\mathrm{Al}_{2} \mathrm{O}_{3}$ additions on the interfacial behavior and mechanical properties of eutectic Sn-9Zn solder on low temperature wetting and soldering of 6061 aluminum alloys. J. Alloys Compd. 2017, 695, 574-582. [CrossRef]

20. Bang, J.; Yu, D.-Y.; Ko, Y.-H.; Kim, M.-S.; Nishikawa, H.; Lee, C.-W. Intermetallic compound formation and mechanical property of $\mathrm{Sn}-\mathrm{Cu}-\mathrm{xCr} / \mathrm{Cu}$ lead-free solder joint. J. Alloys Compd. 2017, 728, 992-1001. [CrossRef]

21. Yang, M.; Cao, Y.; Joo, S.; Chen, H.; Ma, X.; Li, M. $\mathrm{Cu}_{6} \mathrm{Sn}_{5}$ precipitation during Sn-based solder/Cu joint solidification and its effects on the growth of interfacial intermetallic compounds. J. Alloys Compd. 2014, 582, 688-695. [CrossRef]

22. Yang, M.; Ko, Y.-H.; Bang, J.; Kim, T.-S.; Lee, C.-W.; Li, M. Effects of Ag addition on solid-state interfacial reactions between $\mathrm{Sn}-\mathrm{Ag}-\mathrm{Cu}$ solder and Cu substrate. Mater. Charact. 2017, 124, 250-259. [CrossRef]

23. Ghosh, G.; Asta, M. Phase stability, phase transformations, and elastic properties of $\mathrm{Cu}_{6} \mathrm{Sn}_{5}: \mathrm{Ab}$ initio calculations and experimental results. J. Mater. Res. 2005, 20, 3102-3117. [CrossRef]

24. Nogita, K.; Gourlay, C.M.; Nishimura, T. Cracking and phase stability in reaction layers between $\mathrm{Sn}-\mathrm{Cu}-\mathrm{Ni}$ solders and Cu substrates. JOM 2009, 61, 45-51. [CrossRef]

25. Kim, J.W.; Kim, D.G.; Jung, S.B. Mechanical strength test method for solder ball joint in BGA package. Met. Mater. Int. 2005, 11, 121-129. [CrossRef]

26. Kim, J.W.; Jang, J.K.; Ha, S.O.; Ha, S.S.; Kim, D.G.; Jung, S.B. Effect of high-speed loading conditions on the fracture mode of the BGA solder joint. Microelectron. Reliab. 2008, 48, 1882-1889. [CrossRef]

27. Gain, A.K.; Zhang, L. Harsh service environment effects on the microstructure and mechanical properties of Sn-Ag-Cu-1 wt \% nano-Al solder alloy. J. Mater. Sci. Mater. Electron. 2016, 27, 11273-11283. [CrossRef]

28. Gain, A.K.; Zhang, L.; Quadir, M.Z. Thermal aging effects on microstructures and mechanical properties of an environmentally friendly eutectic tin-copper solder alloy. Mater. Des. 2016, 110, 275-283. [CrossRef]

(C) 2018 by the authors. Licensee MDPI, Basel, Switzerland. This article is an open access article distributed under the terms and conditions of the Creative Commons Attribution (CC BY) license (http://creativecommons.org/licenses/by/4.0/). 